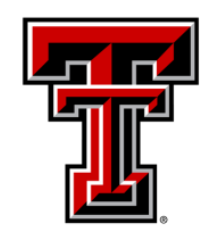

TEXAS TECH UNIVERSITY

Libraries"

\title{
BEHAVIOR UNDER THE CONDITION OF ANONYMITY: A VISUAL ANALYSIS
}

The Texas Tech community has made this publication openly available. Please share how this access benefits you. Your story matters to us.

\begin{tabular}{|l|l|}
\hline Citation & $\begin{array}{l}\text { Schneider, A., \& Turner, T. (2017). Behaviour under the condition of } \\
\text { anonymity: a visual analysis. Visual Studies, 32(2), 148-155. } \\
\text { doi:10.1080/1472586x.2017.1323558 }\end{array}$ \\
\hline Citable Link & $\underline{\text { http://hdl.handle.net/2346/73440 }}$ \\
\hline Terms of Use & $\underline{\text { CC-BY }}$ \\
\hline
\end{tabular}




\title{
Behavior under the Condition of Anonymity: a Visual Analysis
}

\author{
Andreas Schneider (Ph.D., Indiana University) \\ Associate Professor \\ Fulbright Scholar \\ Texas Tech University, \\ Department of Sociology \\ 2500 Broadway, Holden Hall 70 \\ Box 41012, Lubbock, TX 79409-1012, USA \\ andreas.schneider@ttu.edu \\ 8067624932
}

Tom Turner

Adjunct Professor for Photography

The Art institute of San Antonio

10000 IH-10 West \#200, San Antonio, TX 78230, USA

tom@tomturnerphotography 


\title{
Behavior under the Condition of Anonymity: a Visual Analysis
}

\begin{abstract}
Analyzing photographs of abandoned hotel rooms, we forensically classify hotel guests who left their rooms into three ideal types. Goffman's idea of impression management is central for indicating ideal-type specific behavioral motivations. Under the condition of relative anonymity provided in hotel rooms, the audience for which guests manage impressions is either absent or the guests themselves who construct it. In the case of an audience to be seen as relevant it is either an internalized audience, guiding one's behavior, or it is a real audience. We demonstrate that it is possible to classify guests according to forensic analysis of the clues that identify their behaviors as (1) authentic, that is independent from an audience, (2) guided internally by an imagined audience, or (3) influenced by the perception of a real audience. The sociological categories of power and status are used to systematically differentiate behaviors of our three ideal-typical classes of hotel guests.
\end{abstract}

Keywords: Visual Sociology, Forensics, Impression Management, Anonymity, Photography, Ideal Types 


\section{The origin of our idea}

In 1960, author John Steinbeck set out on a journey across America with a standard size poodle named Charlie. The narrative of his journey is published his 1962 book, Travels With Charlie. Shortly after setting out, he stopped in Chicago to see his wife and largely due to his dislike of traffic and a certain eagerness to see his bride, he drove into Chicago very early and arrived at the hotel before most of the guests had checked out. After threatening to sleep on the sofa in the lobby Steinbeck was able to convince the hotel staff to let him rest and get cleaned up in the room of a guest who had left even earlier than he had arrived. The only catch was that the room had not yet been remade. He arrived in the room and began to take off his clothes to get into the shower but before he was able to get both boots off he began to look around and discovered a man he named Lonesome Harry. Steinbeck searched the room for signs of who Harry was and what he did while in Chicago. Harry, an alias to allow the real Harry anonymity, was a nervous man. We know this because he signed his name over and over on the hotel stationary. Steinbeck seemed to think this indicated a sign that he was not that sure of himself in the business world. Harry had a lady visitor who left the smell of perfume on the pillow and who was not his wife because Harry went through more than one draft of a letter to his wife. Three things "haunted" Steinbeck about Lonesome Harry; "First, I don't think he had any fun; second I think he was really lonesome, maybe in a chronic state and third, he didn't do a single thing that couldn't be predicted - didn't break a glass or a mirror, committed no outrages, left no physical evidence of joy." (Steinbeck, [1962] 1997: 90-92).

\section{Brief history of travel accommodations}

The inn has been a common stopping place for travelers since well before the Roman Empire; it would seem that as long as humans have been travelers there have been places of refuge and refreshment for them to stop at. The Ottoman Empire, who had extensive trading routes, funded a form of inn known as a han (Kolodziejczyk, 2000: 178). This tradition of publicly sponsored wayfarer shelters made its way to Britain and through British North America in the $16^{\text {th }}$ century in the form of the public house. While a private citizen could take in and house boarders they couldn't sell them any supplies or alcohol. If you were the proprietor of a licensed public house you could do all of these things (Snadoval-Strausz, 2007: 187). This effectively solved the problem of travelers by both giving them some place to stay as well as giving them something to do, nameley drink.

The word hotel made its way into the English language in the 1760's from the French term hôtel, a word for townhouse, or grand home of a nobleman. The English word came to mean a guesthouse of splendor and high quality. Soon English architects were constructing distinct hotels. The structures were much grander containing bedchambers, dining rooms, ballrooms, dancing halls, and assembly rooms, setting forth new functions for these buildings that hold even today (Snadoval-Strausz, 2007: 6). The construction of America's first Hotel, the Union Public Hotel in Washington D.C., began in 1793 but due to financial issues it was not 
ready to open until well after the United States Government moved to the area in 1800 and thus came in second place to the City Hotel in New York City whose construction began in late 1793 and opened for business in the fall of 1794 (Snadoval-Strausz, 2007: 23-24).

Common law of innkeepers is a series of legal precedents that govern the practice of hotels. This body of rules applies to inns, taverns, and hotels and can be broken into three categories: bed, board, and hearth. The first common law is to provide a bed for anyone who is willing to pay a reasonable price. Many states in the U.S. added these rules to their governing statutes. The second common law is to offer the guest and his livestock food or board. The final element of the common law of innkeepers is that of hearth or refuge. As travelers are particularly vulnerable to theft and violence it is the responsibility of the innkeeper to protect their guest. (Snadoval-Strausz, 2007: 189). This series of common laws represents a social obligation to the travelers by the community as they pass through. Hotels are still required to obtain a license from local governments, which implies an understanding by the communities to abide by these laws.

In 1921 the first Federal Aid Highway act passed through the U.S. Congress granting states a total of $\$ 75$ million to improve their road systems. Shortly after this, in 1926, a man named Arthur Heineman opened the Milestone Mo-tel in San Luis Obispo, California. The word motel is a contraction of the words motor and hotel, and by 1950 there were 28 recognized names for hotels and motels on the Federal Highway guide (Jakle et a. 2002: 18-19).

\section{People in the hotel}

With travel accommodations firmly established, people away from home take new liberties. According to a study by the online travel organization Orbitz "half of Americans who stay in hotels admit they do things on vacation that they don't do at home" (Orbitz 2004). As symbolic interactionist we ask: who are the actors in the hotel room?

The entire staff of a hotel is tasked with the job of promoting a positive impression of the establishment. If there is a spill the hotel staff will clean it up. If you need more towels in your room, no questions are asked - they bring you more towels. If there is a disturbance in the back of the hotel restaurant it is immediately hushed up. Every action is calculated to keep the guest from seeing behind the façade of the operation. Receptionists dominate the stage; in more upscale establishments they are supported by concierges and porters called bellboys, or in the US, bellhops, and room service waiters. While we might speak of a hotel maid who often combines service and arrangements of the suites in the most glamorous hotels, we generally refer to housekeeping for the employees who clean and arrange the rooms. While guests might run into the housekeeping personnel in the hallway janitorial work or gardening is largely invisible. It will be the housekeeping personnel that witness the condition of the hotel room when engaged in their cleaning and rearranging of the rooms. Assuming that guests are not observed through the windows of their rooms, and neglecting ear witnessing other guests, 
housekeeping is the only audience of the behavior hotel guest display in their rooms. Since this observation is indirect through the clues hotel guests leave in their rooms, guests can manipulate the insight of their audience by choosing to avoid creating clues, laving them or remove them. In our investigation we can only observe what guests leave for room service, their audience.

With such a restricted audience, paired with the ability to control the information presented to this audience, guests can either try maintaining the identities that they take outside of the hotel or they can break out of this grip of the ordinary. Prichard and Morgan (2006) argue for the latter:

"I don't know why it happens exactly; all I know is that something strange occurs to guests as soon as they check into the hotel. For some reason, even if in real life they are perfectly well mannered, decent people with proper, balanced relationships, as soon as they spin through the revolving hotel doors the normal rules of behavior no longer seem to apply." (Pritchard \& Morgan, 2006, p. 767; (Edwards-Jones \& Anonymous, 2004, p. 150-151)

\section{Surveillance, anonymity and the internalization of the audience}

Expressed pointedly: people who say that they do not care about others are either autistic or they lie. We all care. But what happens in situations where we assume to be anonymous? Do we still perform acts of impression management to keep a facade even though there is no audience? That largely depends on the degree to which we internalize the audience. Once an audience is internalized it is just as relevant for our impression management as a real audience is. Not everyone, however, will internalize an audience. Here lies an important variation and we argue that the degree to which people internalize audiences provides clues for the classifications of their personalities. It can be argued that internalizing audiences is a product of social control to which people are subjected.

For audiences to become internalized moral or behavioral guidelines have to be presented, and behavior has to be observed and sanctioned. In this socialization process, surveillance is a two-sided sword. With one side it strikes collecting the hard facts that can be used to control, with the other side it strikes in a way that appears far less bloody. This second side of the blade makes subjects compliant to an audience that they think they internalized by free will. Surveillance, real or imagined as ever-watching Gods, angels, or ghosts, makes people comply by internalizing the audience. Surveillance is an important means in the exercise of power in institutions (Foucault 1977). Surveillance turns the superior into the audience of the inferior. Providing surveillance, however, is a costly process. To increase efficiency, modern systems of authority support the internalization of an audience. Decreasing the efforts necessary in maintaining physical surveillance, the internalization of an audience is the most efficient product of surveillance. In this recursive relationship (Giddens, 1979) physical surveillance necessary if the exercise of power is replaced by self-guiding behavior. This reciprocal relationship explains the irony that self-actualization is one of the mantas recited to implement self-censorship and surveillance. 
Such profound institutional efforts leave their mark on the individual's subjective experience to be watched. Some people still live under the delusion that God watches them, a principle in religion that was emphasized, if not created, by rulers to secure their power. Some see Big Brother peeking on them through the uncountable surveillance cameras they face in their daily lives, others might feel to be subjected to both: secular and religious surveillance. "The first premise is that human beings act towards things on the basis of the meanings that the things have for them." (Blumer, 1969, p. 2). The perception of surveillance - delusive or real - is systematically relevant for people's actions.

While hotel rooms are free of direct surveillance, action is not fully anonymous. Guests can assume their rooms to be scrutinized after they leave. Pragmatists know that if they do not create excessive damage that forces room service to report to the hotel management they will be anonymous to the real audience. With their audience they have a power deal. The more they pay, the more service they expect. If they see their power as being higher than the power of the audience, their behavior will be unaffected by the audience. Conversely, if they see their power to be lower than the power of the their audiences, they will subject to external guidance of their behavior.

It might be argued that pragmatists in general rely less on status differentials than ideologists. More specific, in the situation as a hotel guest the occupational prestige score of housekeeping is so low that hotel guests will rarely see themselves below the status rating of housekeeping personnel. For that reason it is predominantly the power differential that affects the degree of anonymity for the pragmatist, and this in turn determines if an audience is experienced. In other words, pragmatists know that if they keep their behavior in boundaries it will not under the scrutiny of an audience. While pragmatists most likely respond to differences on the power dimension, ideologists focus on status differentials. In the extreme form, ideologists divide the World into good and bad, and the good is guiding their behavior. They follow the higher cause often in neglect of the consequences that can be forced upon them. For ideologists the internal audience will always be present and true anonymity will never exist.

If people see their statuses and power to be higher than the statuses and power of internalized audiences and if they see their power to be higher than the power of a potential real audience, their behavior is internally guided and hereby lacks the influence of an audience. This perceived absence of an audience provides anonymity, which is, of course, subjective and might even be seen as a delusion.

\section{Audiences in the dramaturgical approach}

Goffman's (1956) dramaturgical perspective defines a stage on which three parties are involved in interaction. The identity presented by the person, the identity presented by the other person, and the audience witnessing the interaction.

"On the stage one player presents himself in the guise of a character to characters projected by other players; the audience constitutes a third party to the interaction - one that is essential and yet, if the stage performance were real, one that would not be there" (Preface p. I). 
Reducing complexity, Goffman merges the other and the audience into one entity:

"In real live these three parties are compressed into two; the part one individual plays is tailored to the parts played by the others present, and yet these others also constitute the audience." (Goffman 1956, Preface p. I).

In our analysis of a situation where the other is only present through the imagination of the person we differentiate the other and the audience as two different audiences. The real audience - the housekeeping personnel - and an audience the person has internalized. We operationalize our differentiation by considering the relative power and status of the person and the real and internalized audiences. Persons will perceive a real audience if the power of the real audience is higher than the power of a potentially internalized audience. Conversely, they will consider an internalized audience if they see the internalized audience as more powerful and of higher social status than the real audience.

While internalized or real audiences are perceived as external guidance guarding stage performance, performers might experience an audience entirely through the use of their own characters. Internalized and real audiences disappear and subjective authenticism arises when

"a performer may be taken in by his own act, convinced at the moment that the impression of reality which he fosters is the one and only reality. In such cases we have a sense in which the performer comes to be his own audience; he comes to be performer and observer of the same show" (Goffman 1956, p.49).

Neglecting real or the imagined audiences as external guidance, performers act entirely on their characters and hereby become authentic in their actions. We again use empirical concepts of power and status when speaking of authenticism if the performers' statuses and power are perceived as higher than the statuses and power of real and internalized audiences.

\section{Audiences and impression management}

The degree to which people perceive real and/or internalized audiences determines their degree of impression management. If there are real audiences, the need to manage impressions for the audiences' observation is obvious. If audiences are internalized we have an imaginary audience that at first sight might not be as demanding of impression management as real audiences. We, however, think that it would be a mistake to downplay the influence of internal audiences on the degree of impression management. If people perceive others as present these others are real in their consequences. The widely shared imagination of God's present is a good example of how illusions become real in their consequences. People were willing to give their lives to such imaginations and with their actions have created the most horrific bloodsheds in human history.

To the degree that people take themselves as an audience, they act authentic and need not engage in impression management as long as the situation allows for anonymity. An autistic person is an example where authenticism is presented 
without differentiation in situations that allow anonymity and situations where people are clearly observed. In the analysis of abandoned hotel rooms we can use the differentiation of presence or absence of impression management to find and interpret clues left by the guests. To the degree people do not engage in impression management they see their selves as an audience and act authentic. If people engage in impression management we can assume that they perceive an internalized and/or real audience.

\section{Schematic of Ideal Types and its Application}

We define anonymity as the subjective absence of an audience. This subjective presence or absence of an audience is determined by setting statuses and power of the real audience in relation to the status and power of the person. These power and status relations define our schematic of three ideal types where people are pragmatic, ideological or authentic. While the pragmatists and the ideologues will use audiences for the external guidance for their behavior, authenticists will use their own selves to guide their actions (Table 1).

Table 1 to be placed here

Our investigation is a merger of photographic arts and sociology. The artistic part is the esthetics provided by the social usage of public places. Here we observe abandoned hotel rooms in search for signs that can identify pattern of use that in turn allow a generalized classification of users.

For our collection of photographic images of abandoned hotel rooms we identified 90 operating hotels/motels within the city limits of Lubbock, Texas, 81\% of which are franchise hotels and 19\% were non-franchise hotels. We chose 10 of these 90 establishments using a representative match in room rates. The front desk employee and/or the hotel manager were approached in person by the researcher with the request to photograph abandoned hotel rooms before they were cleaned.

The hotel room offers the investigator a blank canvas - cleaned and reset after each use to observe the occupant's behaviors. By exploring the images of hotel rooms after the occupants had left and without communicating with them prior to the investigation we are largely excluded subject effects. There is no reason to believe that guests' behaviors were influenced by our investigation. If they were going to leave the room with their shoes in the trashcan (Figure 1) then that is what the investigator will see. Thus, all impressions are based on their real responses to staying in the room and vacating it as a normal part of their travels.

Figure 1 to be placed here

The second author, formerly an MFA student of photography and now Adjunct Professor of Photography, took artistic images of the hotel rooms and 
selected 23 images which he saw as representing residues of social action. This set of images was subjected to the analysis by the first author.

\section{Results}

Our schematic of the perception of audiences allows us to investigate the fundamental question raised by Gosling (2008): "do the signs we let others see reflect valid information about us, or are they all part of an elaborate act aimed at portraying ourselves as we wish to be seen?" We will not be able to provide an answer to the underlying fundamental question of sociology if human action is authentically constructed or if humans just follow scripts or roles. Instead we hope to shed light on the role of the audience that guides people's behavior under the condition of anonymity. We investigate if their behavior can be identified by the clues they leave in an abandoned hotel room and if this information is sufficient in classifying the hotel guest's personality (Gosling et al. 2003).

Following our schematic in the perception of audiences introduced above, the importance of the audience for the hotel guests is largely determined by the social status and power of the housekeeping personnel in relation to the social status and power of an internalized audience, and to the hotel guests themselves. The schematic of the perception of audiences and the consequent degree of impression management guides our selection of clues from artistic photographs of abandoned hotel rooms.

If a guest did not see a relevant audience and left the towel where it fell, we expect to have a clear clue in the photographic image of the abandoned hotel room. But can we see if someone folds her towel tidily for the internalized audience (e.g., God) or for the real audience, the housekeeping staff? Differentiating the obedience to internal versus external audiences just on this basis will be a more challenging task than identifying independence of the actor.

\section{Identifying pragmatism}

External and internal guidance of action is differentiated by the locus of the audience. People lacking a salient internal audience or do not have the power to stand up to their own ideals to be authentic, will take the perspective of the real audience. While it might seem to be in principle more rational using the standards of a real audience than using one's own imaginations as a substitute audience, in the case of relative low power people's actions will be very similar in the sense that they will obey an outer directive. Since the choice of internal audiences is likely to be socialized it will create normative behavior, just as we expect it from an ordinary hotel guest with no excessive power or status.

Still we expect small differentiations between pragmatists and ideologists in the nature of the action. When considering a real audience, the audience will be accommodated in a more specific orientation. It is not the neatness at which towels are arranged, but the practicality of the arrangement for the housekeeping staff that shows the consideration of the real audience. It is not the gracefulness of 
appearance that might serve the real persons involved with housekeeping, but the degree to which their job is being made easier.

Potential clues: Towels are hung for easy pick up by housekeeping. Small washing towel is placed on the bathtub shelf placed for easy pick up. Towel is places on the countertop for easy pick up and (same picture, but out of focus) soda cans and bottles deposited in the trashcan for convenient disposal.

Figure 1 to be placed here

\section{Identifying ideology}

Behaviors of ideologists are guided by statuses and principles of higher order. This could be esthetics, but more likely it is religion. Our observation took place in the Western part of Texas where Christian religion is omnipresent. It is, therefore, not far fetched to assume that hotel guests see God watching them. Neatness and gracefulness should glare into the eye of the Lord. Even if the internalized audience is secular, behaviors will not be contextually tailored towards the real audience of housekeeping but follow abstract aesthetic principles.

Potential clues: towels neatly folded on the alarm clock, beer bottles and plastic cops equally spaced from the central water faucet. Empty plastic cup centrally placed on top of the room save.

Figure 2 to be placed here

\section{Identifying authenticism}

If the behavior of hotel guests is not guided by an internalized audience or by their concern of their behavior being of consequence of the housekeeping staff, they act authentic. In this case we assume their social status and potency to be higher than the social status and power of the housekeeping staff. With housekeeping personnel not likely to be perceived as an important audience, guests tend to use the anonymity provided by the hotel room to behave as they please.

Under anonymity, the only confinement for the guests' action could be their own standards or the standards they see set by an internalized audience. If guests see their status and power as higher as that of an alternative entity, they will not internalize such entity as an audience for their actions.

Potential clues: towels on floor, Champagne bottles instead of beer bottles twisted lamp shades (Fig 3), shoes in trash (Fig 4),

Figure 3 to be placed here 
Figure 4 to be placed here

\section{Conclusion}

Through the hotel room travelers in purgatory are rescued and find sanctuary and rest. They bring their bits of hopes, dreams and detritus that provide signs not only of individuals, but also of the culture that provides the pattern for actions of individuals. These pattern are largely structured by the power and social statuses of individuals. Power and social status are not only properties of an individual they are shared by classes of people and are, therefore, central aspects of sociological analysis. Suitable for us, since we do not investigate the person per se, but ask "what kind of person" leaves a hotel room in the way we see it in the image. Since it is the individual who acts and leaves the clues in our images, our analysis has to be engaged in both: abstraction and deduction. First, when we created categories we use abstraction, then in the analysis of images we used these abstract categories to search for visual traces left by the individual.

In this search for clues we tab into a rich source of data. Whatever we do, we leave traces of our actions. Which action does not leave a trace? In the advent of the Internet there was a widespread naïve assumption to have anonymity on the web. Today we know better, we have always left traces in Cyberspace, it just needed an agency with the resources and the interest to use these traces in order to create profiles of regularities of whatever boogey man they decided to go after. The unrestrained "yes we can mentality" during the Obama administration extended the usage of criminal forensics from the investigation of the usual suspects to all citizens in the World (Greenwald, 2014). Today, anonymity remains mainly an illusion.

Every traveler leaves traces. The scrutiny we use in the analysis of pictures pales when compared to the depth of forensic analysis. Not restraint by concerns about human subjects and with budgets unlikely to be provided for the social sciences, criminal forensics confirmed multiple traces of sperm in the bedroom in which Strauss-Kahn, head of the International Monetary Fund (IMF) and the leading candidate for the French presidency, allegedly engaged in inappropriate sexual behavior (Barron 2011). DNA analysis of these traces in his hotel room identified seven different men besides Strauss-Kahn. It is unlikely that in his $\$ 3,000$-a-night Sofitel suite the bed linens were not changed. Modern forensic analysis went well beyond the analysis of a fingerprint to traces that are absolutely impossible to be detected by the human eye.

With the financial resources provided for analysis with criminal forensics the depth of the investigation possible by technology, an overwhelming detail of information is collected. With the nearly unlimited resources provided to the National Security Agency (NSA) of the US for the analysis of big data, experts start to believe that this magnitude of produced data is exactly the shortcoming of the methodology. While our analysis of images of abandoned hotel rooms in principle 
employed forensic methodology, we took the challenge of using minimal information for maximum generalization. By nature such endeavor has its limitations.

\section{Limitations}

Our analysis of images is clearly limited. Having developed a classification scheme based on status and power we are investigating the images for clues that could categorize the guests into authentic or being guided by real or internal audiences. While such classification is illustrative, it lacks the degrees of freedom for a reliable determination. For such deterministic judgment the instrument - the classification scheme - needed to be tested empirically by obtaining measures of power and status of hotel guests.

Our conclusion suggests that an interpretation of any photographic image is de-facto an imagination of the researcher. While these imaginations can be well guided and inspiring, they are not objective in the positivistic sense. Using stringent categorizations or other systematics should not delude ourselves that any information beyond the researcher's interpretation of the picture has to come from an empirical investigation.

This problematic of subjective reality is investigated by Luisa Allen (2012) using methodological triangulation. Not only did she analyze the pictures that her subjects took of their life circumstances, but she interviewed her subjects as well. These interviews provided information allowing her to rule out potentially misguiding interpretations. She also used these insights to systematically critique four different approaches to the interpretation of photographic images. With the objective information provided by the subjects she realized discrepancies that led to the rejection of the realist approach that sees images as evidence of something. She critiques the interpretivist approach that a picture is an interpretation of reality and the performative reading of images, stating that a photo only starts to exist in our discourse. In her investigation she finds most merit in the idea of materializing reading, which sees the interpretation of a photo as evolutionary process in which the researcher's perspective is applied in the research process. With her interpretation of the perspectives on image analyses she is in agreement with our conclusion that no matter how much we try to structure our investigation, at the end of the day it is the interpretation of the researcher that is presented in the analysis.

Our conclusion and Allen's constructive critique on the analysis of images makes it clear that it would be inappropriate comparing the reliability our analysis to an empirical investigation. In contrast, comparison to other constructions of reality might provide a more appropriate assessment of our analysis. Let us take the classic examples of coroners and juries as interpretations considered to be valid in the legal application. Coroners are professionals while juries are lay people. Garfinkel ([1967] 1984) stated that 95\% of what jurors do is to apply their commonsense knowledge. Developing and using a classification scheme in our 
analysis we certainly went beyond this level of lay investigation of a jury, that nevertheless is sufficient to support an induce of a court ruling. Being paid professionals, coroners should be expected to be more rigid in their methodology. Atkinson (1978) demonstrated that in their investigation of suicide coroners employed commonsense interpretations and theorizing. Once clues are selected building up a picture that passes a level of plausibility that might be shared by the courts, this picture becomes official evidence. Obviously coroners cannot interview the dead to validate their clues.

While our investigation of hotel rooms and the classification of hotel guests easily meets the criteria of truth that is employed in criminal cases in the courts, a triangulation with empirical methodology would certainly provide insights that would be beneficial in establishing the instruments for the young discipline of visual sociology.

\section{References}

Adams, Douglas. 1986. The Ultimate Hitchhicker's Guide (Vol. 1). New York, NY, USA: Wings Books.

Allen, Louisa. E. 2012. Schools in Focus: Photo methods in educational research. In S. Delamont (Ed.) Handbook of Qualitative Research in Education (pp. 241-251).

Northampton, Massachusetts: Edward Elgar Publishing Limited.

Atkinson, John. M. 1978. Discovering Suicide: Studies in the Social Organization of Sudden Death. London: Macmillan.

Barron, James. 2011. “The Guests Who Never Left Strauss-Kahn's Hotel Room.” New York Times. August 23.

Foucault, Michel. 1977. Discipline \& Punish: The Birth of the Prison. New York: Vintage Books.

Garfinkel, Howard. 1984 [1967]. Ethnomethodology. Cambridge: Polity Press.

Gosling, Samuel D., Peter J. Rentfrow, and William B. Swann. 2003. "A very brief measure of the Big-Five personality domains." Journal of Research in personality 37,6:504-528.

Gosling, Samuel. D. 2008. Snoop: What Your Stuff Says About You. New York, NY, USA: Basic Books.

Greenwald, Glenn. 2014. No Place to Hide: Edward Snowden, the NSA, and the U.S. Surveillance State. New York: Metropolitan Books. 
Orbitz 2014. Orbitz's "Hotel Habits" Survey Reveals Americans' Sneaky Vacation, Behavior. Chicago, IL April 26, retrieved July 27th, 2015, from http://press.orbitz.com/phoenix.zhtml?c=251693\&p=irolnewsArticle_Print\&ID=1795471.

Jakle, John A., Keith A. Sculle, and Jefferson S. Rogers. 2002. The motel in America. JHU Press.

Kolodziejczyk, Dariusz. 2000. Ottoman-Polish Diplomatic Relations (15th-18th Century): An Annotated Edition of 'Ahdnames and Other Documents. Boston, USA: Brill.

Pritchard, Annette, and Nigel Morgan. 2006. Hotel Babylon? Exploring hotels as liminal sites of transition and transgression. Tourism Management, 27:762-772.

Snadoval-Strausz, Andrew K. 2007. Hotel: An American History. New Haven , CT, USA: Yale University Press.

Steinbeck, John. 1997. Travels With Charlie In Search Of America. New York, USA: Penguin Group. 
Table 1: Schematic of Ideal Types defined by Status and Power Relations with their Audiences

\section{External Guidance}

Real Audience will be chosen if

Power of Internalized Audience < Power of Real Audience $\Rightarrow$ Pragmatist

Internalized Audience will be chosen if

Status of Internalized Audience > Status of Real Audience $\Rightarrow$ Ideologist

\section{Internal Guidance}

The self will be chosen as an audience if

Power of Self $>$ Power of Real Audience AND

Status of Self $>$ Status of Internalized Real Audience $\Rightarrow$ Authenticist 


\section{Behavior under the Condition of Anonymity}
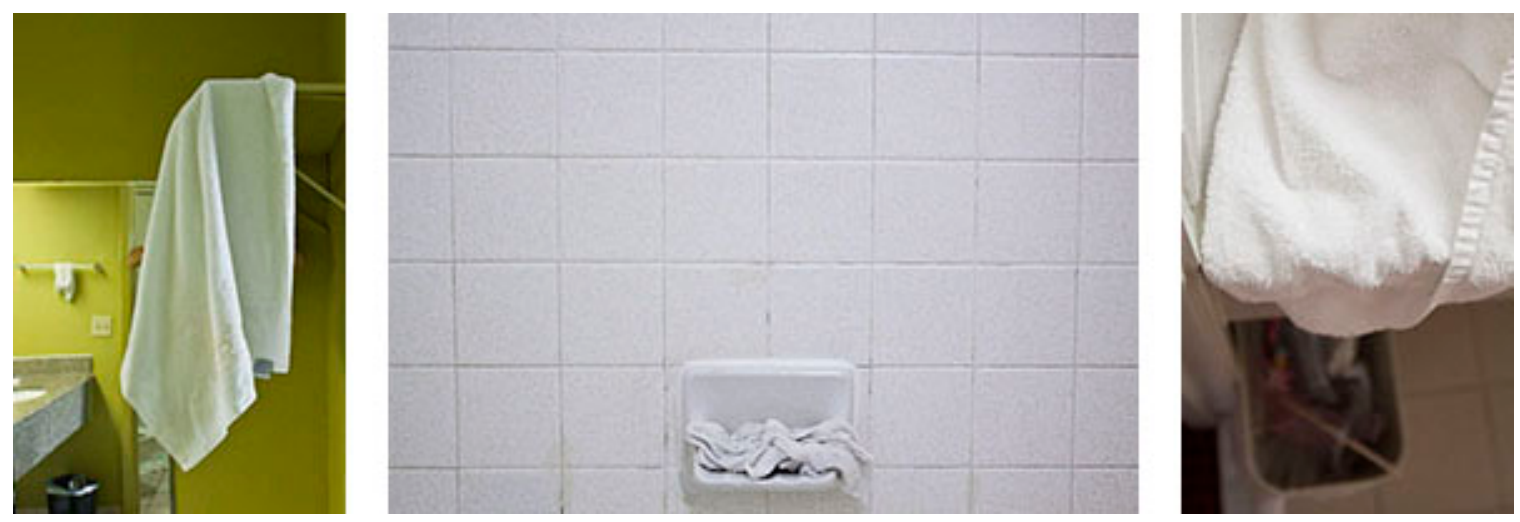

Fig. 1 Pragmatist: Power of Internalized Audience < Power of Real Audience
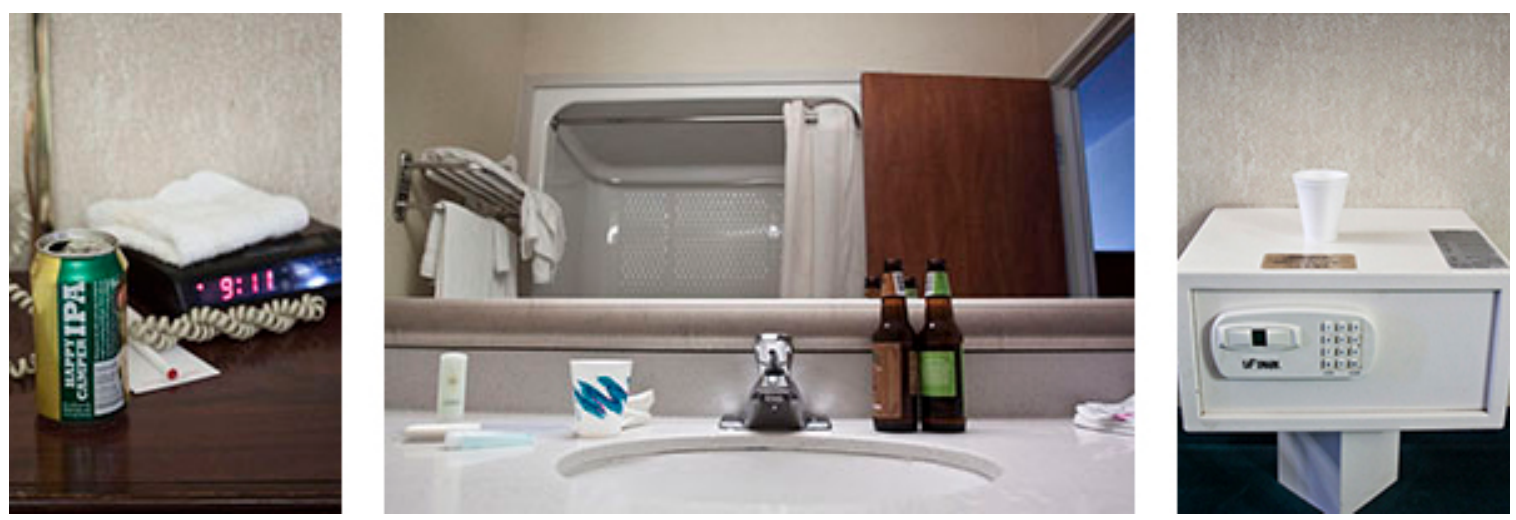

Fig. 2 Ideologist: Status of Internalized Audience > Status of Real Audience
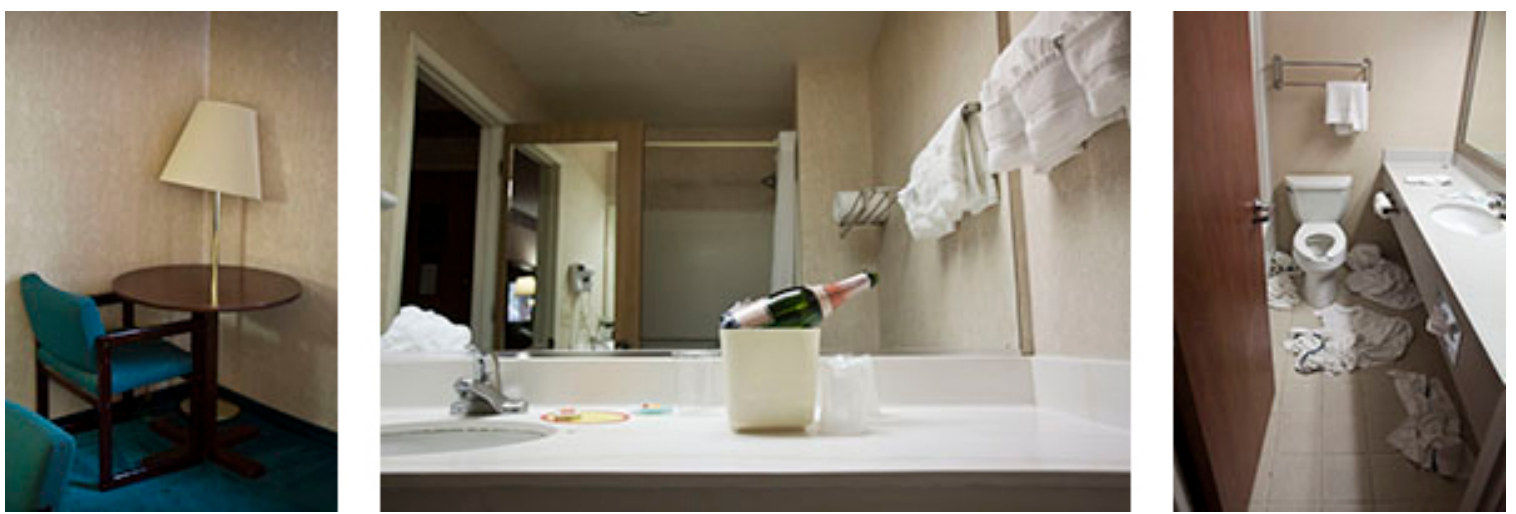

Fig 3 Authenticist: Status of Self $>$ Status of Real Audience AND Power of Self > Power of Internalized Audience 


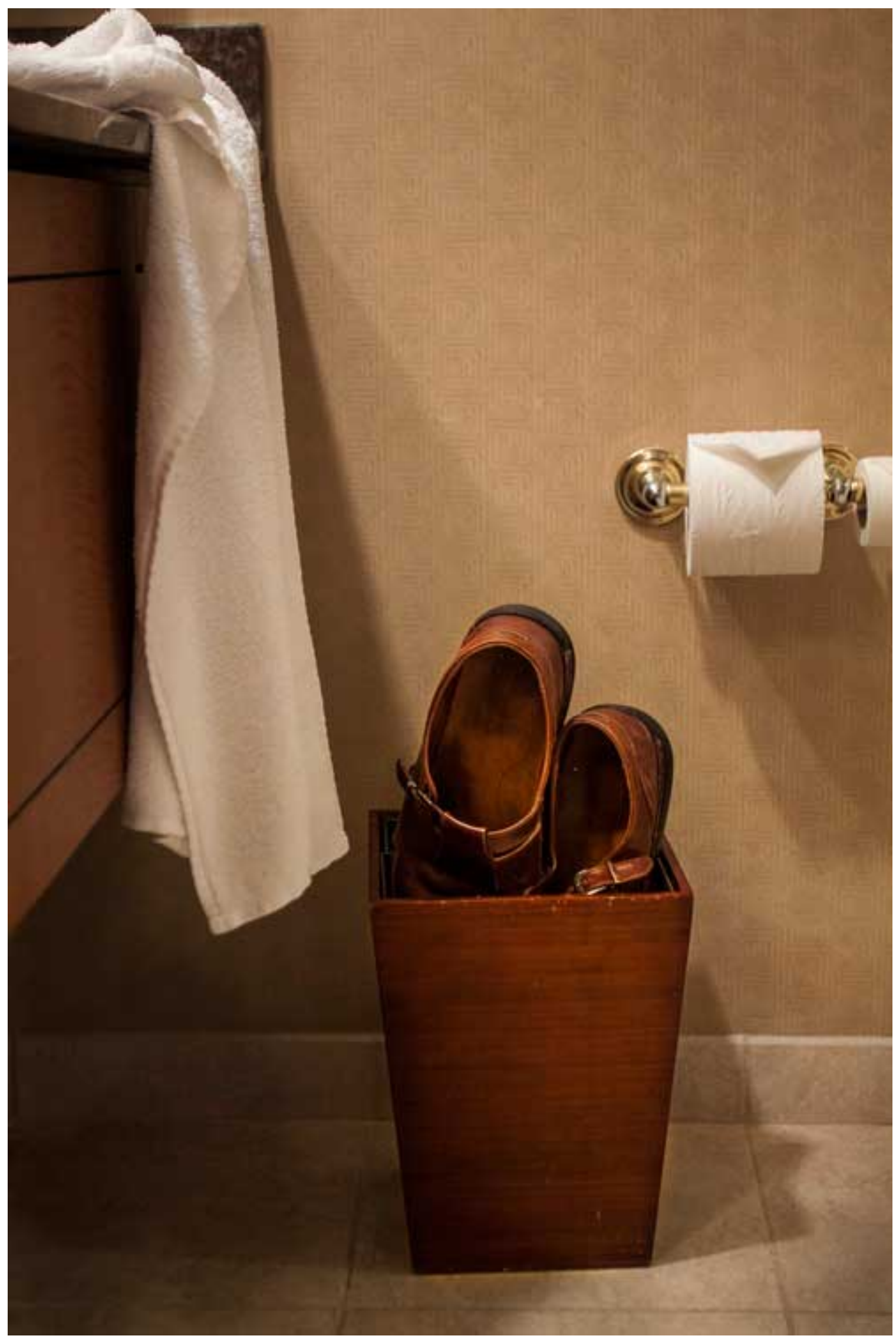

Fig. 4 Shoes in Trashcan 